\title{
The Electrodeposition of Gold by Pulse Plating
}

\section{IMPROVEMENTS IN THE PROPERTIES OF DEPOSITS}

\author{
Ch. J. Raub and A. Knödler
}

Forschungsinstitut für Edelmetalle und Mctallchemie, Schwäbisch Gmünd, West Germany

\begin{abstract}
The replacement of a direct by a pulsed current in the electrodeposition of gold has a marked effect in improving the mechanical properties of the deposits and in reducing their internal stresses. For many applications in the electronics industry pulse plating therefore offers considerable advantages.
\end{abstract}

The use of pulsed current is well known as a research tool for studying the electrodeposition mechanism of metals. With increasing emphasis on the properties of the deposits, however, it was realised that this method of deposition could well provide a means of improving their properties. It was observed some years ago that either by periodically reversing the polarity of the current or by applying pulsed current, deposits of a much finer grain size could be obtained from cyanide (1) or from acid copper electrolytes $(2,3)$, and this has since been confirmed by other research workers for nearly all electroplated metals (3-10). The influence of pulsed current on the properties of chromium, for example, is especially interesting, since its structure and properties, including internal stresses, are strongly influenced by the form of the applied current $(11,12,13)$.

It has also long been known that the structure and surface roughness of gold and gold alloy deposits can be influenced by periodically reversed or pulsed current, but this interest developed greatly when it was realised that pulse plated gold deposits proved superior to D.C. plated deposits for certain electronic applications, a discovery which was carefully followed up at Western Electric and from whence nearly all the information published on the industrial application of the pulse plating of gold has come.

According to Avila and Brown (8) industrial pulse plating was first attempted at the Western Electric Engineering Research Center, Princeton, New Jersey, in June 1967. In the following year apparently the need for a high conductivity gold electrodeposit for integrated circuitry initiated the development of a pulse plating unit which supplied an on-off D.C. pulse with on- and off-times in the millisecond range and operated with current peaks up to $8 \mathrm{~A}$. In general the on- and off-times were in the range of $1: 10$. The advantages claimed for the pulse plating of gold were:

(1) A substantial increase in rate of deposition.

(2) Less danger of hydrogen embrittlement.

(3) A reduction in the need for additives.

(4) A lower level of impurities from the electrolyte.

Pulse plating of gold in the production of semiconductor devices seems to be a procedure which is comparable to vacuum deposition but much more convenient and rapid, especially for experimental purposes (16).

One of the direct industrial applications of pulse plating is the "beam-cross over plating" on a thinfilm circuit. This technique enables the crossing of conductor paths on a thin-film circuit such as is shown in Figure 1. There can be as many as 2500 crossovers on a substrate. The dimensions of the

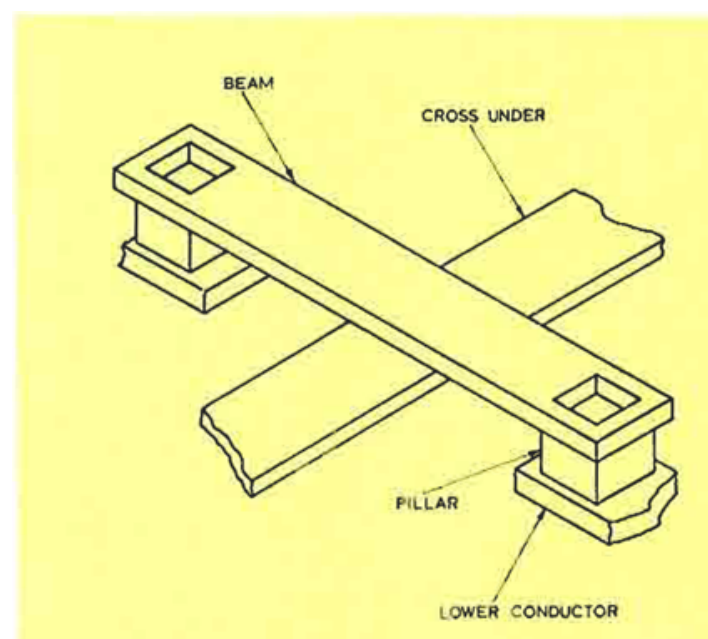

Fig. 1 Sketch of a beam erossover. The number of crossovers on a substrate may vary up to $\mathbf{2 5 0 0}$ 


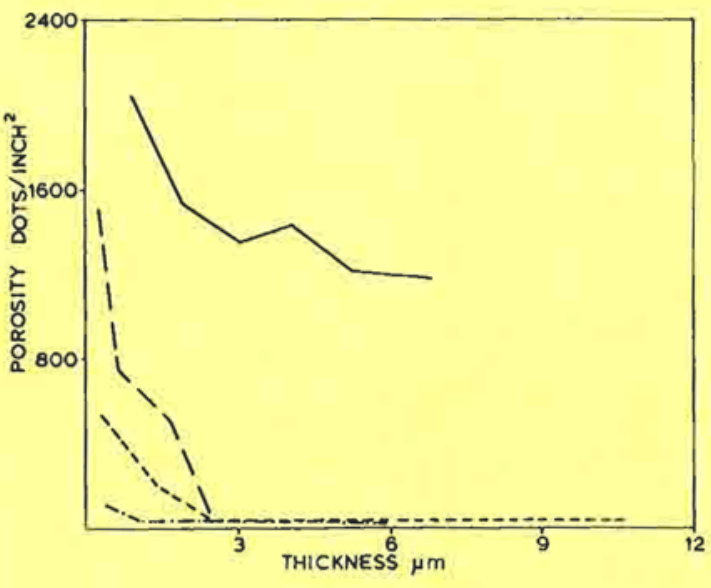

Fig. 2 Relationship between porosity and thiekness of various types of gold films according to Rehrig (15)

$$
\text { electron gun evaporation }
$$$$
\text { - }
$$$$
\text { - - - - - D.C. plating }
$$$$
\text { _...... P.C. plating }
$$

crossover are, for example 8 mil wide, 50 mil long, and of the pillars $3 \times 5 \mathrm{mil}$ (14). It was quite a problem to ensure good plating into the hole and to establish good contact of the beam to the pillar. By using pulse plating this problem was solved. Also it was possible to avoid unnecessary edge build-up (dog boning) of beam and lower conductor which might cause clearance and breakdown problems in thin film circuitry.

Among the advantages of pulse plating a higher rate of deposition is often included (8). By using for example 8 to $10 \mathrm{~A} / \mathrm{ft}^{2}$ pulsed current instead of 4 to $5 \mathrm{~A} / \mathrm{ft}^{2}$ Pcihoda and Walker (14) were able to reduce plating time by half. Cheh (17) has done theoretical calculations and experimental measurements which clearly show that for phosphate, citrate and cyanide gold electrolytes the limiting current density is higher in pulse than in D.C. plating because of the higher concentration of gold ions in the diffusion layer, although the limiting over-all plating rate is lower. According to Cheh this increase in the limiting current density might be the reason for the improved physical properties by yielding a different type of structure in the deposit.

\section{Properties of the Deposits}

From the results of a number of investigations it is clear that pulse plating markedly affects the properties of the deposit. It was discovered in the early days that pulse plating of fine gold deposits produces a dense fine-grained structure with about half the resistivity of normal D.C. plated layers (8). The fact that pulse plated deposits have the lowest porosity of all gold films deposited by various methods was attributed by Rehrig (15) to the densely packed continuous fine grained structure with barely visible grain boundaries. One of his graphs is shown in Figure 2. The very small grain size and the high purity also serve to explain the difference in tensile strength and elongation observed by Lendvay and Raub (6) and shown in Figure 3. In the as-deposited condition fine-grained deposits gave a tensile strength about 25 per cent higher than with D.C. plated deposits, while elongation increased by a factor of 2 . D.C. plated deposits show a slight increase in tensile strength after heat treatment at $100^{\circ} \mathrm{C}$, which is followed by a continuous decrease at higher temperatures, while elongation rose more or less steadily. The increase at $100^{\circ} \mathrm{C}$ is very likely due to the beginning of decomposition of incorporated impurities. Pulse plated deposits with lower impurity concentrations do not show any hardening effect. As one might expect from a purer metal, its tensile strength also decreases much more rapidly during heating.

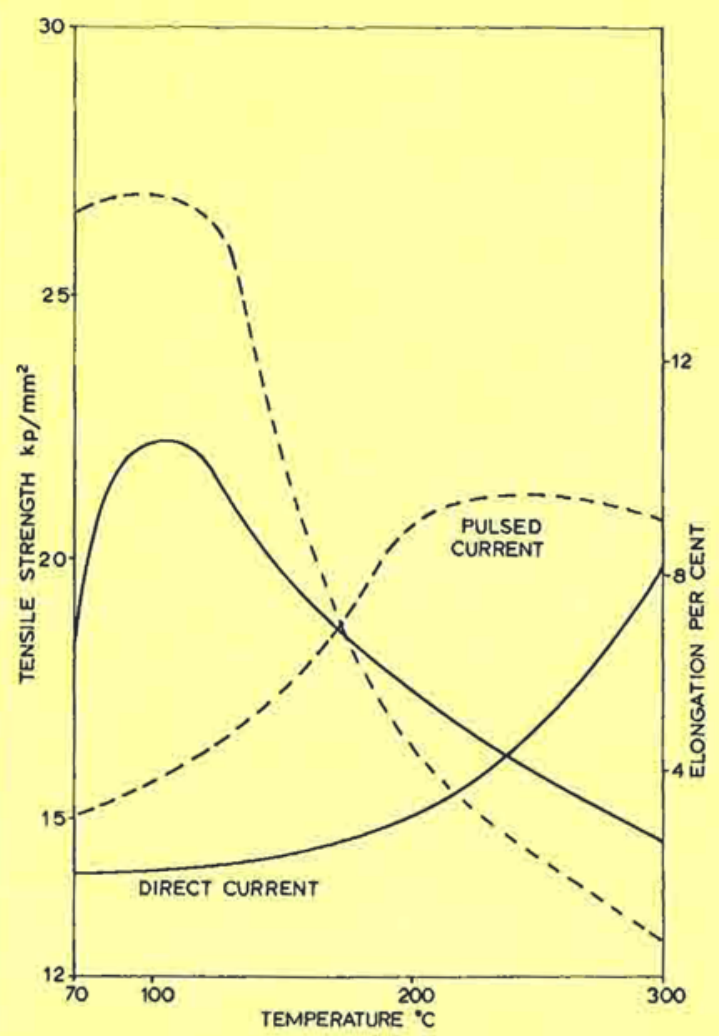

Fig. 3 Tensile strength and elongation of pulsed current and direct current plated deposits from a phosphate gold solution (20 $\mu \mathrm{m})$ 
The higher conductivity of pulse plated deposits has already been mentioned. The results for deposits from phosphate electrolytes have been supported by similar measurements on deposits from citrate baths (18). In the latter case pulse plating reduced resistivity from 3 to only $2.4 \mu \Omega \mathrm{cm}$.

\section{Electrodeposited Alloys}

Because of their importance for the electronics industry nearly all work on the properties of pulse plated gold alloys has been centred around the acid gold-nickel and gold-cobalt electrolytes. Reid (18) studied the influence of pulse plating on the inclusion of the organic polymer, discovered first by Miss Munier (22), and on the mechanical and electrical properties, while Knödler in these laboratories $(19,20)$ investigated its influence on chemical composition, internal stresses and hardness. In addition, the crystallographic properties of gold-nickel deposits from an alkaline electrolyte have also been studied by Viswanathan and Raub (7).

Since we wish to discuss the pulse plating results of these investigators in more detail, we have to describe their experimental set-up. In both cases rectangular pulses with on-times of about 1 to $10 \mathrm{~ms}$ and off-times of about 5 to $100 \mathrm{~ms}$ were used. The average current density I (comparable to the D.C. current density) is calculated from:

$$
I=i_{p} \frac{t_{\text {on }}}{t_{\text {on }}+t_{\text {off }}}
$$

where $i_{p}=$ pulse current density

$$
\begin{aligned}
& t_{\text {on }}=\text { on-time } \\
& t_{\text {off }}=\text { off-time }
\end{aligned}
$$

For comparison purposes deposits with the same average current density as in direct current plating were prepared.

For the semiquantitative determination of polymer, Reid (18) developed a gravimetric method by dissolving the gold deposit in aqua regia. After careful washing and drying the polymer residue was sucked through a filter-stick and weighed. In this way Reid could determine the total amount of residue insoluble in aqua regia, but not its composition. Knödler (19) on the other hand determined the base metal and the carbon, hydrogen, oxygen and nitrogen contents of pulse plated gold alloys. It was observed that at low current densities and low $t_{o n} / t_{\text {off }}$ ratios the presence of polymer could be nearly eliminated.

Its amount increased with thickness and with current density, while the brightness of the deposits decreased; deposits free from polymer were semimatte at $20 \mu \mathrm{m}$. From the dissolution experiments it was concluded that in pulse plated gold the polymer is no longer distributed continuously, as observed by Antler (23) in D.C. plated deposits, but discontinuously. This much lower polymer concentration and its different distribution also have a strong influence on other properties of the deposit. Ductility determined by $180^{\circ}$ bending tests is also increased; on the other hand, tensile strength is nearly unchanged and elongation is increased to about 2 per cent (24), but internal stresses are drastically reduced. Hardness changes little or even increases by pulse plating.

It is well known that the density of gold-cobalt deposits $\left(\sim 17 \mathrm{~g} / \mathrm{cm}^{3}\right)$ is about 15 per cent lower than the theoretical value, due to voids or inclusions. Pulse plated gold-cobalt layers-nearly free from polymer-have a density of $19.2 \mathrm{~g} / \mathrm{cm}^{3}$, very close to the theoretical, as determined by the pycnometer method (18).

The reduction of resistivity by pulse plating is even more pronounced for gold-cobalt deposits than for fine gold layers, as shown in Figure 4. This decrease is very interesting since it must be caused by the reduction in polymer or by microstructural differences only, because the cobalt concentration of pulse plated deposits is greater by 25 per cent (18). From other measurements it may be concluded that most of the cobalt is present in form of a solid solution with gold $(25,26)$ and that this increase in cobalt concentration should cause a comparable increase in resistivity. Resistivity values for metallurgically prepared gold cobalt alloys $(0.25$ per cent $\mathrm{Co})$ are about $6 \mu \Omega \mathrm{cm}(21)$. At present this behaviour is being studied in more detail in our laboratory.

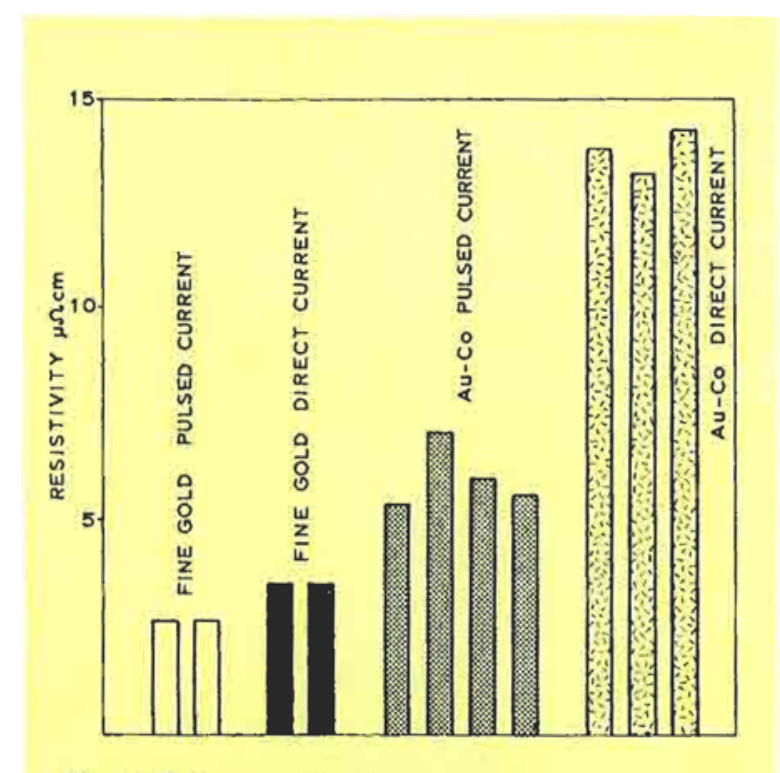

Fig. 4 Influence of pulse plating on the electrical reisistivity of pure gold and of gold-cobalt alloy electrodeposits according to Reid (18) 


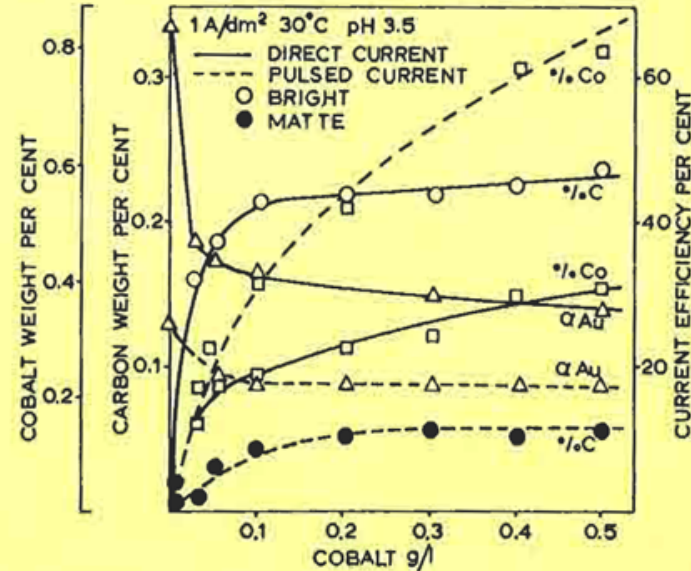

Fig. 5 Cobalt and carbon contents, and current efficiency of direct current and of pulsed current plated gold-cobalt deposits as a function of cobalt concentration of the electrolyte

In X-ray investigations a high degree of orientation in the pulse plated deposits was discovered. In addition to the $\{111\}$ orientation, the $\{410\}$ orientation showed up in pulse plated gold-cobalt deposits, while the 50 per cent $\{200\}$ orientation present in D.C. plated deposits disappeared. An additional orientation by pulse plating also occurs in gold-nickel alloys from cyanide electrolytes; apart from the normal $\{110\}$ direction pulse plated deposits exhibit a $\{111\}$ orientation.

A very detailed study on the influence of pulse plating on the composition and properties of goldcobalt, gold-nickel, gold-iron and other gold alloys was recently carried out by Knödler (19). The results show quantitatively that by pulse plating the amounts of cobalt and nickel are increased drastically by factors of about 2 and 4 respectively and that the carbon concentration, caused by the polymer, is reduced to only about 20 per cent of the value for D.C. deposits. Furthermore, the current efficiency of pulse plating is only about 60 per cent of D.C. plating. Nearly all gold-cobalt deposits prepared by pulse plating are matte or semi-bright as shown in the solid circles in Figure 5.

The main difference between gold-cobalt and goldnickel deposits is that the latter are bright in a wide range of depositing conditions in contrast to the former alloys, as shown in Figure 6 . The changes in carbon and nickel concentrations are similar to those observed with gold-cobalt electrolytes.

The temperature dependence of the impurity concentrations is very similar for pulse plated and D.C. plated deposits, cobalt concentration and current efficiency changing little up to $60^{\circ} \mathrm{C}$, and carbon concentration decreasing with temperature. At 50 and

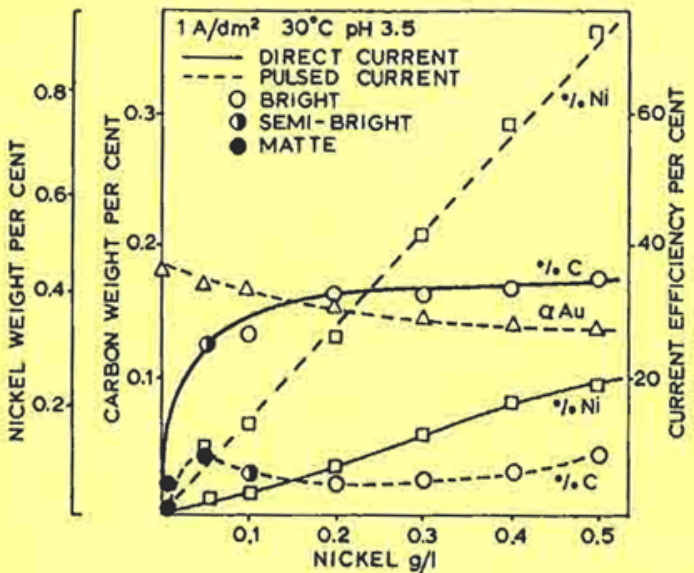

Fig. 6 Nickel and carbon contents, and current efficiency of direct current and of pulsed current plated gold-nickel deposits as a function of nickel concentration of the electrolyte

$60^{\circ} \mathrm{C}$ pulse plated deposits are semi-bright. In goldnickel alloys (Figure 7) the nickel concentration increases with temperature up to about 2.5 weight per cent of nickel at $60^{\circ} \mathrm{C}$. The current efficiency is independent of temperature, but the carbon concentration goes through a minimum at 0.04 weight per cent at $40^{\circ} \mathrm{C}$. This minimum is not observed in D.C. plating (20).

There seems to be a slight reduction in brightness at higher temperatures for pulse plated gold-nickel deposits. A decrease in on-time and a simultaneous increase of pulse current density, while keeping off-

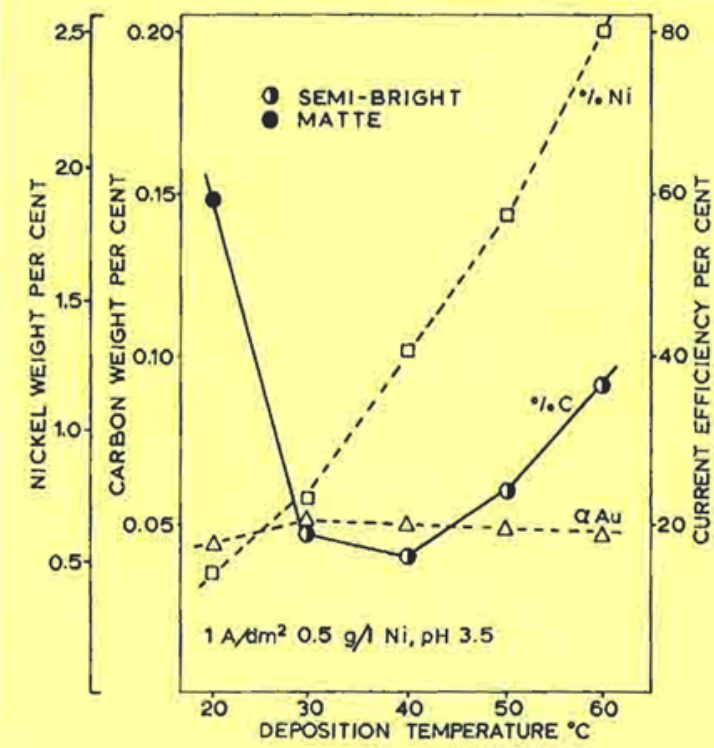

Fig. 7 Nickel and carbon contents, and current efficiency of pulsed current plated gold-nickel deposits as a function of temperature of deposition 


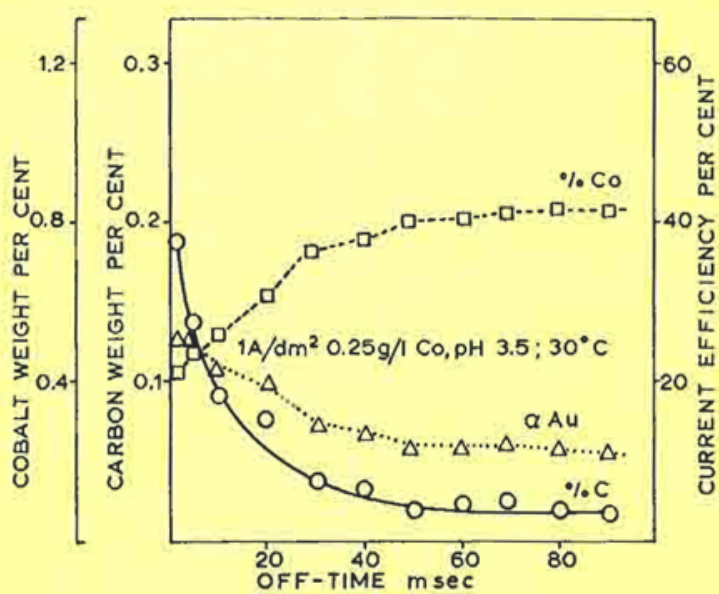

Fig. 8 Cobalt and carbon contents, and current efficiency of pulsed current plated gold-cobalt deposits as a function of off-time

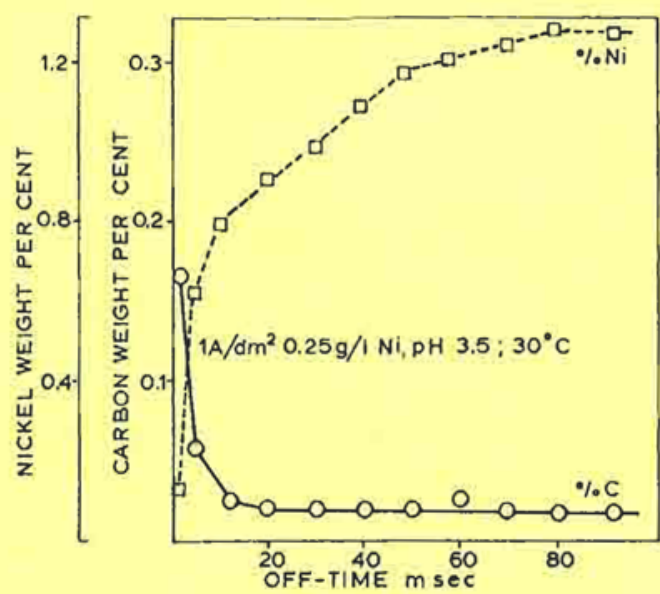

Fig. 9 Nickel and carbon contents of pulsed current plated gold-nickel deposits as a function of off-time time and average current density constant, increase the cobalt concentration and cause the current efficiency to drop, while the carbon content remains unchanged. There is no difference between 20 and $50 \mathrm{~ms}$ off-time. The gold-nickel deposits show a minimum of 0.8 weight per cent nickel at $i_{p}=$ $30 \mathrm{~A} / \mathrm{dm}^{2}$. Raising the average current density at constant $i_{p}$ decreases the cobalt content and increases

Table I

Gas Concentrations of Pulse Plated GoldCobalt Deposits

Electrolyte $0.5 \mathrm{~g} / \mathrm{l} \mathrm{Co} ; \mathrm{I}=1 \mathrm{~A} / \mathrm{dm}^{2} ; \mathrm{pH}=3.5 ; 30^{\circ} \mathrm{C}$

\begin{tabular}{|c|c|c|c|c|}
\hline & \multirow{2}{*}{$\begin{array}{l}\text { IP.C. } \\
\mathrm{A} / \mathrm{dm}^{2}\end{array}$} & \multicolumn{3}{|c|}{ concentration, ppm } \\
\hline & & $\mathrm{H}$ & $\mathrm{N}$ & 0 \\
\hline Off-time & 5 & 146 & 307 & 151 \\
\hline \multirow[t]{4}{*}{$20 \mathrm{~ms}$} & 10 & 142 & 274 & 142 \\
\hline & 20 & 110 & 255 & 141 \\
\hline & 30 & 159 & 257 & 164 \\
\hline & 40 & 104 & 316 & 175 \\
\hline \multirow{5}{*}{$\begin{array}{c}\text { Off-time } \\
50 \mathrm{~ms}\end{array}$} & 5 & 167 & 374 & 181 \\
\hline & 10 & 174 & 386 & 195 \\
\hline & 20 & 145 & 336 & 190 \\
\hline & 30 & 129 & 331 & 169 \\
\hline & 40 & 148 & 311 & 168 \\
\hline \multicolumn{2}{|c|}{$\begin{array}{l}\text { Direct current } \\
1 \mathrm{~A} / \mathrm{dm}^{2}\end{array}$} & 560 & 1083 & 503 \\
\hline \multicolumn{2}{|c|}{$\begin{array}{l}\text { Concentration } \\
\text { C }_{\text {D.c. }} / \mathrm{C}_{\mathrm{P} . C .}\end{array}$} & $\sim 3.5$ & $\sim 3.5$ & $\sim 3.3$ \\
\hline
\end{tabular}

the carbon content almost linearly. Increasing offtime has just the opposite effect, as shown in Figure 8. The gold-nickel deposits behave very differently (Figure 9); the nickel concentration increases much faster to a higher value, while the carbon values fall faster with off-time.

As in an earlier paper on D.C. plated deposits (20) we also studied the gas content of pulse plated deposits. The results are shown in Table I for gold-cobalt and in Table II for gold-nickel alloys. It is found that for gold-cobalt alloys-independent of the nature of the gas concerned and within the scatter of the results-the ratio $\mathrm{C}_{\mathrm{D} . \mathrm{C} .} / \mathrm{C}_{\mathrm{P} . \mathrm{C}_{\text {. }}}\left(\mathrm{C}_{\mathrm{D} . \mathrm{C} \text {. }}\right.$ $=$ concentration in D.C. plated deposits, $C_{P . C .}=$ concentration in pulse plated layers) is nearly the same $(\sim 3.5)$ as it is for the carbon concentration ( 4.5). For gold-nickel deposits (Table II) this ratio is again fairly independent of the element, also about 3, depending slightly on the nickel concentration of the electrolyte. This observation suggests that the incorporated polymer in goldcobalt and gold-nickel deposits is similar.

Electrodeposited metals and alloys often show fairly high internal stresses, which among other causes can be brought about by co-deposited impurities. An influence of pulse plating on the stress of hard gold deposits might well be expected, and, as can be seen in Figure 10, there is a marked reduction in the internal tensile stresses of gold-cobalt and gold-nickel deposits. Bright layers with nearly zero stress can be produced from gold-nickel electrolytes by pulse plating. We are at present investigating to what thicknesses these results can be extended, but it should be borne in mind that low-stress deposits generally have high cobalt and nickel concentrations. This 
shows that the stress in hard gold alloys is primarily caused by the co-deposited non-metallic inclusions and not by the base metal additions.

The hardness of pulse plated gold-cobalt deposits is about 10 per cent higher than that of comparable D.C. plated alloys. This is probably also due to the higher base metal concentrations.

In reviewing the data on pulse plating it has to be borne in mind that three effects are unique:

(1) Due to the high current pulses high deposition potentials are obtained which strongly favour the co-deposition of the less noble metals cobalt and nickel.

(2) During off-times the depleted concentration of metal ions in the cathodic layer can be replenished by diffusion.

(3) During off-times, by-products formed during the cathodic discharge can diffuse out of the cathodic layer, thereby reducing their codeposition.

Without going into details, we can thus explain the fact that in pulse plating the decisive effects are the restoring of the diffusion layer during off-times by gold and cobalt complexes and the removal of byproducts consisting of hydrogen, oxygen, carbon and nitrogen compounds from the cathode film. Without a knowledge of the diffusion coefficients of the various ions and/or radicals involved, more detailed explanations have to remain somewhat speculative. The pulse plating results strongly support the idea, however, that the co-deposited material is mostly an organic compound, containing fairly little cobalt or gold. The influence of cobalt may be a predominantly catalytic one. The earlier

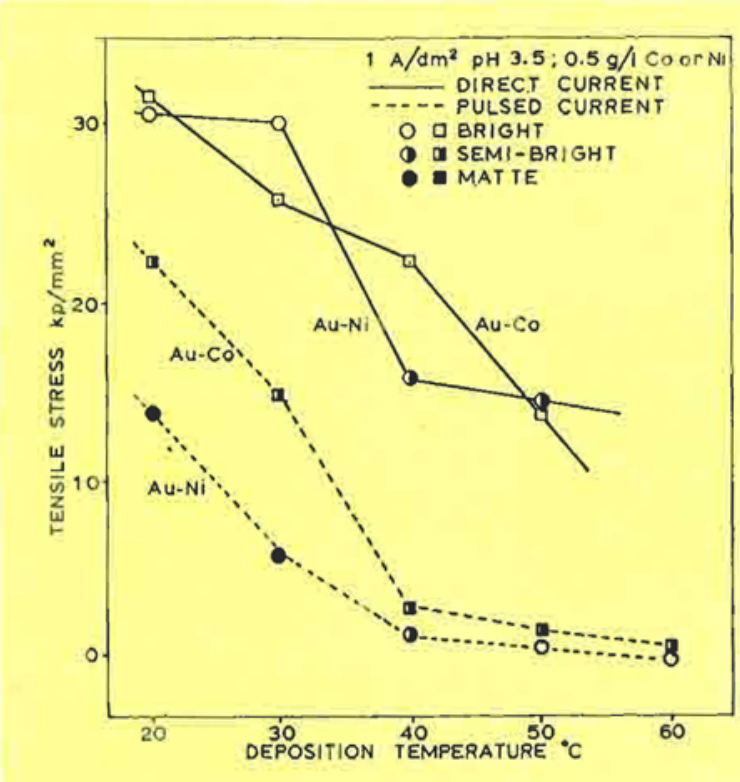

Fig. 10 Tensile stress of direct current and pulsed current plated gold-cobalt and gold-nickel deposits

observation that gold-nickel electrolytes behave differently has been confirmed.

\section{Conclusions}

This discussion of the literature and of our own work on the pulse plating of gold and gold alloys has shown that it is possible to obtain deposits having properties which are superior to those of deposits obtained by normal D.C. plating. This method also makes possible the production of nearly stressfree deposits, while it also seems to furnish better microthrowing power of the electrolytes.

Table II

Gas Concentration of Gold-Nickel Deposits with Increasing Nickel Concentration of the Electrolyte $\mathrm{pH} 3.5,30^{\circ} \mathrm{C}$, ID.C. $1 \mathrm{~A} / \mathrm{dm}^{2}, 110 \mathrm{~A} / \mathrm{dm}^{2}$, on time $2.6 \mathrm{~ms}$, off-time $20 \mathrm{~ms}$

\begin{tabular}{|c|c|c|c|c|c|c|c|}
\hline \multirow{2}{*}{$\begin{array}{c}\text { Nickel } \\
\text { concen- } \\
\text { tration } \\
\mathrm{g} / \mathrm{l}\end{array}$} & \multirow{2}{*}{. Current } & \multicolumn{3}{|c|}{ Concentration, ppm } & \multicolumn{3}{|c|}{ CD.C.C/P.C. } \\
\hline & & H & N & 0 & H & N & 0 \\
\hline \multirow[t]{2}{*}{0.1} & D.C. & 279 & 530 & 582 & $\sim 2.2$ & $\sim 1.5$ & $\sim 2.0$ \\
\hline & P.C. & 125 & 360 & 270 & & & \\
\hline \multirow[t]{2}{*}{0.3} & D.C. & 343 & 865 & 485 & $\sim 3.0$ & $\sim 2.5$ & $\sim 2.5$ \\
\hline & P.C. & 122 & 353 & 201 & & & \\
\hline \multirow[t]{2}{*}{0.5} & D.C. & 398 & 945 & 404 & $\sim 5.0$ & $\sim 3.0$ & $\sim 3.0$ \\
\hline & P.C. & 83 & 314 & 138 & & & \\
\hline
\end{tabular}


Pulse plating is also especially valuable for investigating the problem of polymer formation in hard gold deposits. It increases the amount of cobalt and nickel in the deposits drastically, and at the same time reduces their contents of carbon, hydrogen, oxygen and nitrogen. With gold-nickel electrolytes, it is possible by pulse plating to produce bright deposits with high nickel but low polymer concentrations.

\section{Acknowledgements}

The authors wish to express their gratitude to the Chamber of Mines of South Africa for their support of this work.

\section{References}

1 G. W. Jernstedt, Proc. Am. Electroplaters' Soc., 1949, 36, 63; 1950, 37, 151

2 A. P. Popkov, F. Appl. Chem. U.S.S.R., 1966, 39, (8), 1632

3 A. M. Ozerov, N. P. Litvishko, I. N. Vavilina, P. M. Chetvertnov and Ya. E. Zhak, F. Appl. Chem. U.S.S.R., $1967,40,(5), 1101$

4 A. Hickling and H. P. Rothbaum, Trans. Inst. Met. Finish., 1957, 34, 199

5 C. C. Wan, H. Y. Cheh and H. B. Linford, Plating, $1974,61,(6), 559$

6 J. Lendvay and Ch. J. Raub, Metalloberfläche, 1975, 29, (4), 165
7 M. Viswanathan and Ch. J. Raub, Surface Technol $1976,4,(4), 339$

8 A. J. Avila and M. J. Brown, Plating, 1970, 57, (11), 1105

$9 \mathrm{M}$ Viswanathan and $\mathrm{Ch}$. J. Raub, Galvanotechnik, $1975,66,(4) .277$

10 R. I. Gurovich and A. K. Krivtsov, Zh. Prikl. Khim. (Leningrad), 1968, 41, (6), 1227

11 C. L. Faust, G. R. Schaer and D. E. Semones, Plating, $1961,48,(6), 605$

12 A. Knoddler, Galvanotechnik, 1970, 61, (4), 290

13 H. Schreiner and Ch. J. Raub, Z. Werkstofftech., 1975, 6, (12), 414

14 W. W. Pcihoda and A. E. Walker, Electron. Packag. Prod., 1975, 15, (6), 74

15 D. L. Rehrig, Plating . 1974, 61, (1), 43

16 C. A. Burrus, 7 . Electrochem. Soc., 1971, 118, (5), 833

17 H. Y. Cheh, F. Electrochem. Soc., 1971, 118, (4), 551

18 F. H. Reid, Metalloberflache, 1976, 30, (10), 453

19 A. Knödler, Galvanotechnik, 1977, in the press

20 A. Knödler, Metalloberflache, 1974, 28, (12), 465

21 A. S. Darling, Gold Bull, , 1972, 5, (4), 74

22 G. B. Munier, Plating, 1969, 56, (10), 1151

23 M. Antler, Plating, 1973, 60, (5), 468

$24 \mathrm{Ch}$. J. Raub, and J. Lendvay, unpublished results

25 Ch. J, Raub, H. R. Khan and J. Lendvay, Gold Bull., $1976,9,(4), 123$

26 A. F. Mohrnheim, F. Electrochem. Soc., 1970, 117, (6), 833

\section{Automatic Gold Plating of Edge Connectors}

To provide the complex printed circuit boards required for the new reedelectronic TXE4 system adopted by the British Post Office for the modernisation of their telephone networks as well as for military applications a new electroplating facility has been established by Exacta Circuits of Selkirk in Scotland, a subsidiary company of ITT.

To complete the boards, the edge connectors need to be gold plated, and this is carried out in a newly installed automatic plant built by Kirkby Process and Equipment of Liverpool capable of handling 80 to 90 boards per hour. The electrolyte, an acid cyanide cobalt-gold, was developed by Sel-Rex for this type of process. The gold deposits, $5 \mu \mathrm{m}$ in thickness, are tested for porosity and for thickness. The consumption of gold runs to some 30 to 35 kilogrammes a year.

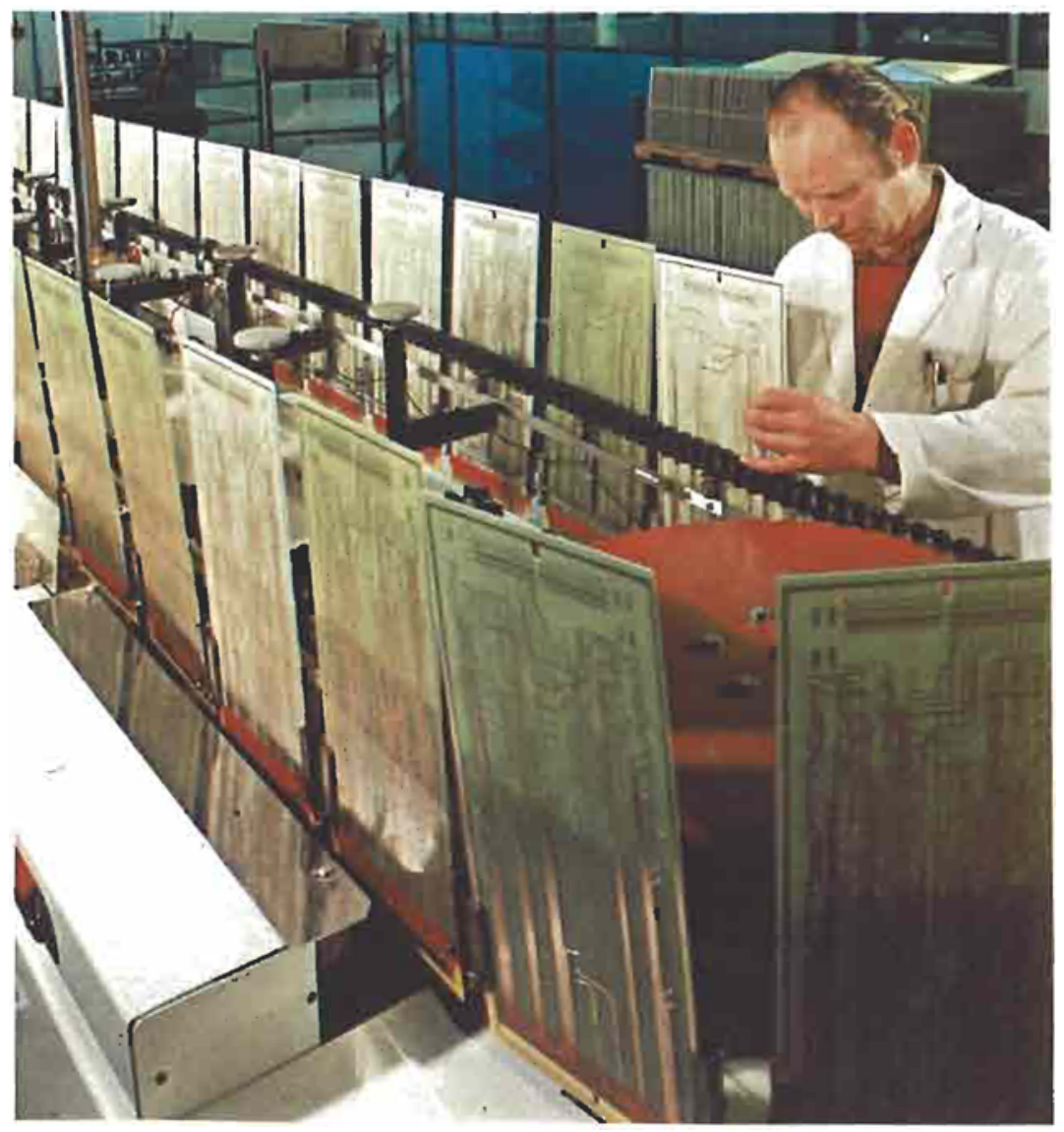

